\title{
DISCIPLINA, VIGILÂNCIA E PEDAGOGIA
}

\author{
ANA LÚCIA SILVA RATTO \\ Departamento de Planejamento e Administração Educacional \\ Setor de Educação, Universidade Federal do Paraná \\ anaratto@ufpr.br
}

\begin{abstract}
RESUMO
Este texto, apoiado em narrativas de livro de ocorrência utilizado em uma escola pública de $I^{a}$ a $4^{a}$ série do ensino fundamental, visa problematizar a dimensão de vigilância exercida pelo tipo de lógica disciplinar que neles se apóia, articulando-a com um certo tipo de tradição pedagógica, ainda fortemente localizável no cotidiano escolar. A perspectiva é a de que tal tradição, apoiada em pressupostos de infantilização das crianças - que enfatizam características universais e necessárias, acentuando traços de dependência, imaturidade e desprestígio acabam por gerar a necessidade de constante vigilância e controle sobre elas por parte das autoridades escolares. Quanto mais há o que vigiar, mais vigilância é necessária e mais se estende o campo para as transgressóes e para a produção da criança indisciplinada. DISCIPLINA - COMPORTAMENTO - ESCOLAS PÚBLICAS - PEDAGOGIA
\end{abstract}

\begin{abstract}
DISCIPLINE, SURVEILLANCE AND PEDAGOGY. This text, based on narratives registered on an "occurrence book" employed by an elementary public school( Ist $^{\text {to }} 4^{\text {th }}$ grades), intends to discuss the level of surveillance exerted by type of disciplinary logic that inspires them, articulating it with a kind of pedagogic tradition, which is strongly attached to the school's routine. The point to be made is that this tradition, supported by ideas that infantilized the children by considering dependency, immaturity and discredit as universal traits of infancy, end up promoting the need of continuous surveillance and control over them by school authorities. The more to survey, more surveillance is in need and more ample the area for transgressions and for the constitution of the undisciplined children. DISCIPLINE - BEHAVIOR - PUBLIC SCHOOLS - PEDAGOGY
\end{abstract}


Neste artigo, buscarei problematizar, com base em narrativas existentes em livros de ocorrência recentemente usados em uma escola pública de Curitiba, a dimensão de vigilância exercida pelo tipo de lógica disciplinar que os impulsiona'. Esses livros constituíram o principal material empírico de minha pesquisa de doutorado ${ }^{2}$, livros estes destinados às crianças de $I^{a}$ à $4^{a}$ série do ensino fundamental, utilizados para registrar e corrigir os comportamentos infantis considerados pelas autoridades escolares como indisciplinados. Trabalhei sobre um universo total de aproximadamente seiscentas ocorrências, referentes a 1998, 1999 e 2000.

Em artigo anterior (Ratto, 2002), construí cenários iniciais para a problematização do funcionamento desses livros de ocorrência mediante a provocação de identificar através deles a circulação de uma espécie de "crimes" e de "pecados", elegendo os elementos confessionais existentes nas narrativas como fio condutor das análises. Nesse sentido, meu foco de atenção não se voltou para avaliar se a escola deveria fazer isto ou aquilo: se a escola deve ou não suspender um aluno que agrediu o colega com uma faixa de pano; se os pais de crianças que quebram o vidro da casa vizinha à escola devem ou não ressarcir o prejuízo; ou se a escola deve ou não conversar com as crianças, conscientizando-as. Também não pressuponho que a escola deva "comemorar" ou "aplaudir" as crianças que brigam entre si, que desrespeitam as autoridades escolares, que gazeteiam aulas ou que são flagradas tomando remédio. A existência de algum tipo de disciplina é mesmo necessária para a vida na escola, a questão é saber qual.

Minha preocupação voltou-se para o apontamento do tipo de lógica que move instrumentos pedagógicos tais como são os livros de ocorrência, para o tipo de pressupostos, relações ou efeitos sobre os quais se apóiam, tendo em vista que eles não são em si mesmos bons ou ruins, uma vez que dependem do contexto em que funcionam. Com isso, a intenção não foi a de reproduzir, em meus questionamentos, mais uma instância de veredictos sobre a escola,

I. Trata-se de uma escola pública de grande porte localizada na periferia de Curitiba, que atende população de baixo poder aquisitivo. Por questões éticas, omitirei qualquer dado que possa, direta ou indiretamente, levar à identificação da escola ou das pessoas envolvidas nos registros das ocorrências analisadas. Aproveito para, mais uma vez, agradecer a disponibilidade da escola, que permitiu o desenvolvimento de minha pesquisa.

2. Trabalho orientado pelo Professor-Doutor Alfredo Veiga-Neto, a quem quero aqui mais uma vez agradecer. 
Disciplina, vigilância e pedagogia

tendo em vista que também ela está inserida em um complexo feixe de relações de poder, de controle e de vigilância que a tornam constantemente culpável. Tudo o que posso imaginar a esse respeito acena no sentido de que esse tipo de reflexão possa trazer elementos utilizáveis, em meio às difíceis decisões que a escola deve tomar diariamente no campo disciplinar e os aviltantes salários recebidos pelos profissionais que nela trabalham.

No caso do artigo mencionado, o tipo de lógica disciplinar ali discutido remete ao pressuposto de que esses livros de ocorrência afirmam, de modo tendencial, a inocência da escola e a culpa das crianças, em um contexto em que as autoridades potencialmente têm o poder de estabelecer a verdade de cada caso. Nesse sentido, especialmente as crianças são objetivadas e subjetivadas a partir do funcionamento diário desse pressuposto da culpabilidade, diferente da responsabilidade como pressuposto e não apenas as que estão presentes nos registros dos livros, mas também o conjunto das crianças que estudam na escola, dado que todas se encontram sob a ameaça de vir a estar neles presentes.

Os elementos da lógica pecaminosa, criminosa ou inquisitorial identificados podem ser também abordados com base nas considerações feitas por Foucault (1977) no âmbito de sua caracterização a respeito das disciplinas. Assim, se nas narrativas dos livros de ocorrência abundam a menção de provas, testemunhos, acusações, veredictos, confissões, desculpas, promessas, tudo isso pode ser reanalisado tendo em vista especialmente a circulação dos elementos constitutivos daqueles três instrumentos que, tipicamente, para Foucault, caracterizam o funcionamento do poder disciplinar: o exame, a vigilância hierárquica e a sanção normalizadora.

Neste artigo, focalizarei a atenção na dimensão de vigilância, exercida mediante os livros de ocorrência, articulando-a com um tipo de tradição pedagógica ainda fortemente localizável no cotidiano escolar contemporâneo.

\section{"SONHO POLÍTICO" DE QUE CADA CRIANÇA SE TORNE SEU PRÓPRIO VIGIA}

$\bigcirc$ que Foucault chama de vigilância hierárquica remete a um universo de técnicas voltadas para a observação - a mais microfísica, extensa e automática possível - dos indivíduos. Funciona como uma espécie de máquina, viabi- 
lizando efeitos de poder contínuos e duradouros sobre os indivíduos. Frise-se que não se trata da crítica a qualquer forma de observação ou de olhar, mas, sim, daquela voltada para a vigilância, no sentido do controle estreito, da normalização das condutas, da detecção e correção de irregularidades.

Trata-se de poderes que visam controlar os corpos por intermédio do olhar, que se dirige ao mesmo tempo sobre todos e sobre cada um. Os livros de ocorrência não existem de modo independente dessa rede de olhares, na medida em que funcionam nessa teia, em meio ao extenso conjunto de instrumentos de disciplinamento em ação, tanto na sociedade, quanto na escola. Os livros agem no sentido de concretizar, especialmente para as crianças, o fato de elas estarem sob constante observação, avaliação e julgamento, com efeitos para muito além dos sujeitos que neles estão presentes, pois as crianças que não estão registradas nos livros sabem muito bem que, poder vir a ser registradas.

Essa rede de vigilância apresenta uma hierarquia. No entanto, por ela circulam relações de poder que, no conjunto, possuem dimensões automáticas e anônimas, já que podem funcionar, a qualquer momento, independentemente dos motivos ou de quem as exerce. $\bigcirc$ caráter extensivo, contínuo, microfísico, tanto do poder disciplinar, de modo geral, quanto especificamente da rede de vigilância hierárquica, age conforme o "sonho político" de que cada criança se torne seu próprio vigia, mediante a interiorização desses olhares - e do conjunto dos mecanismos pelos quais o poder disciplinar circula - dentro de si.

A eficácia do poder [disciplinar], sua força limitadora passaram, de algum modo, para o outro lado - para o lado de sua superfície de aplicação. Quem está submetido a um campo de visibilidade, e sabe disso, retoma por sua conta as limitações do poder; fá-las funcionar espontaneamente sobre si mesmo; inscreve em si a relação de poder na qual ele desempenha simultaneamente os dois papéis; torna-se o princípio de sua própria sujeição. Em conseqüência disso mesmo, o poder externo, por seu lado, pode-se aliviar de seus fardos físicos; tende ao incorpóreo; e quanto mais se aproxima desse limite, mais esses efeitos são constantes, profundos, adquiridos em caráter definitivo e continuamente recomeçados. (Foucault, 1977, p. 178-179)

É importante ressaltar que essa rede de vigilância hierárquica atua fortemente em todos os sujeitos que estão sob sua alçada, não apenas sobre as 
Disciplina, vigilância e pedagogia

crianças. Estudo sobre disciplina feito a partir de pesquisa de campo realizada nos anos 80, em quinze escolas estaduais de ensino fundamental e médio da cidade de Campinas, aponta:

O diretor é um funcionário que tem inúmeras tarefas a cumprir, de caráter essencialmente burocrático; está sujeito a sanções caso não cumpra as ordens superiores. Os processos administrativos parecem ser os fantasmas que pairam constantemente sobre a carreira do diretor. Poucos ousam tomar atitudes fora daquilo que já está determinado. (Guimarães, 2003, p.131)

No Brasil, ainda que os processos de democratização, desencadeados em especial a partir dos anos 80 , tenham trazido as práticas de eleição dos diretores em algumas regiões brasileiras e mesmo que possamos encontrar hoje diretores fortemente comprometidos com a dimensão pedagógica de suas tarefas, ainda é fácil localizar a continuidade de sua inserção em uma cadeia de direitos e deveres, de obrigações e possíveis punições, em caso de descumprimento; um encadeamento em cuja lógica os próprios livros de ocorrência se encontram, tornando vigiável e culpável qualquer um de seus integrantes.

Outro autor que aborda essa dimensão extensiva dos mecanismos disciplinares é Alfredo Furlán. Em "La cuestión de la disciplina: los recovecos de la experiencia escolar" ("A questão da disciplina: os esconderijos da experiência escolar"), texto elaborado a partir de pesquisas em escolas secundárias mexicanas e argentinas, feitas nos anos 90 (cf. Furlán, 2000), ele conclui que, para se proteger da rigidez das normas disciplinares escolares, buscam refúgios tanto os alunos, como os docentes:

A escola trabalha de tal maneira que provoca a necessidade do esconderijo, da construção de uma guarida física e simbólica. Não apenas por parte dos estudantes, mas também dos docentes e autoridades que às vezes buscam proteger-se da rigidez de suas próprias normas. (Furlán, 2000, p. 18, tradução minha)

autor refere-se particularmente às observações sobre esconderijos criados pelos estudantes, como lugares de encontro no "recreio" ou nas horas livres, refúgios prediletos nos quais conversam, namoram ou fumam. Guimarães também se remete a esse tipo de situação, ao apontar que a reclamação 
de não poder fumar nem namorar nas escolas foi generalizada nas entrevistas feitas com os alunos mais velhos de sua pesquisa. Tais proibições foram consideradas injustas pelos alunos, uma vez que, por exemplo, o corpo docente e demais autoridades podiam fumar dentro da escola. "Conclusão, quem fumava e quem namorava continuava fazendo essas coisas, mas pelos cantos escuros e fechados do prédio" (Guimarães, 2003, p.85).

Localizei um exemplo nas narrativas dos livros que vai nessa mesma direção:

Ocorrência I. Aos "x" dias do mês de "x" de "x", a inspetora Claudia veio à Coordenação Pedagógica comunicar que os alunos Damião Guedes Nogueira [aluno citado entre os "campeões de ocorrência"] (série "x") e Cauby M. Antunes [também um dos "campeões de ocorrência"] (série " $x$ ") estavam no corredor do Bloco Cescondidos atrás do flanelógrafo, o que foi por nós constatado. Os alunos deveriam estar na aula de Ed. Física, no entanto, porque o professor Rômulo pediu que os mesmos retirassem os bonés, os mesmos ausentaram-se da aula e começaram a perturbar as turmas do Bloco " $x$ ". Conversamos e o caso será comunicado aos pais. [Constam a rubrica da pedagoga e a data abreviada.] (grifos meus)

Esconderijos e refúgios, assim como o desenvolvimento de outras estratégias cotidianas de resistência a essa rede de vigilância e ao receio generalizado de punições, formam parte de uma cultura escolar na qual as questões

3. As citações do conjunto das ocorrências existentes neste texto são sempre a transcrição literal dos registros, incluindo abreviações, letras maiúsculas e minúsculas, vírgulas, erros gramaticais, de ortografia e quaisquer outras marcas próprias do registro original. A intenção é mantêlo o mais intacto possível. As ocorrências citadas são numeradas em ordem crescente; a numeração está grifada em negrito, para facilitar sua localização, uma vez que, ao longo do texto, será necessário remeter a ocorrências já mencionadas. Quando julguei pertinente, fiz entre colchetes observações, para facilitar a leitura, prestar esclarecimentos ou indicar que há trecho suprimido, tendo em vista o objetivo da citação. Para garantir o anonimato, utilizei nomes fictícios para as pessoas envolvidas, procurando seguir a estrutura da narrativa: quando são mencionados nome e sobrenome, inventei um nome e um sobrenome; se é mencionado apenas o nome, apenas este foi substituído. Em geral, selecionei ocorrências em que as crianças não são reincidentes; se o forem, isso será explicitado na citação, entre colchetes. Quando aparecem, nos trechos citados, a data da ocorrência, a série em que estuda a criança ou qualquer outro dado de identificação avaliado como desimportante ou sigiloso, substituoos pelas letras finais do alfabeto. Por fim, para chamar a atenção, grifei com itálico alguns trechos, tendo em vista o objetivo de cada citação. 
disciplinares são construídas mediante práticas complexas de olhares desde os primeiros anos da escolarização, práticas pelas quais especialmente os estudantes, mas não só eles, podem a qualquer momento ser colocados no "banco dos réus", como já foi observado. A lógica disciplinar aí presente funciona sobre a premissa de que todos devem ser em alguma medida vigiados, como estratégia garantidora de que os comportamentos esperados e exigidos serão praticados e como ameaça de que os desviantes serão detectados e corrigidos.

No caso dos livros de ocorrência que pesquisei - e tendo em vista o contexto abrangente do disciplinamento geral efetuado pela escola -, é significativa sua eficiência relativa, podendo ser apontada pelo baixo índice de reincidência das crianças, ou na medida em que a maioria delas faz sua trajetória escolar sem ter passado pelos livros. Por exemplo, em 1998, 474 nomes de crianças são citados nos livros de ocorrência "completos", incluindo-se aí os nomes das crianças reincidentes ${ }^{4}$. Se tomamos por base um número total de 1.500 matrículas nos turnos da manhã e da tarde, esses 474 nomes de crianças citadas representariam apenas cerca de $32 \%$ desse total; e se tomamos por base um número total de 2 mil matrículas ${ }^{5}$, representariam 24\%.Ou seja, mais de $70 \%$ do alunado que freqüenta essa escola não está presente nos livros de ocorrência.

A significativa dimensão de eficiência desses livros de ocorrência também pode ser visualizada pelos baixos índices de reincidência das crianças. Por exemplo, em 1998, daqueles 474 nomes de crianças citadas, apenas aproximadamente $15 \%$ são de crianças que reincidiram duas vezes ou mais nos livros. Ou seja, para a grande maioria do alunado, assinar o livro de ocorrências uma única vez tende a ser algo forte o bastante para produzir efeitos corretivos duradouros em sua conduta.

4. Nesta escola, havia dois tipos de livros", referentes a 1998, 1999 e 2000, um que chamei de "completo", destinado às faltas "mais graves", apresentando uma estrutura narrativa mais constante e detalhada, cujos registros em geral ficavam sob a responsabilidade das pedagogas, e outro, de "resumido", com narrativas sucintas e geralmente usado para os problemas disciplinares "mais banais" ocorridos durante o recreio, troca de docentes, entrada e saída da escola, registrados pela "coordenação administrativa". Realizei um mapeamento minucioso das 570 ocorrências existentes nos livros "completos", referentes a 1998 e 1999, estabelecendo marcos iniciais para a análise quantitativa e qualitativa e uma tipologia de situações e conseqüências narradas nos registros. Para maiores detalhamentos, ver minha tese de doutorado (Ratto, 2004).

5. Tendo em vista que, em uma caracterização, nem sempre o anonimato garante a não identificação da escola, preferi contextualizá-la por uma descrição às vezes baseada em números aproximados, como é o caso do número total de matrículas existentes. 
A rede disciplinar é tanto mais eficiente quanto mais se aproxima daquele ideal da interiorização plena, voltado para a máxima incorporação possível dos dispositivos de controle e de vigilância no interior de cada sujeito. E, para tanto, a escola desenvolve diversas estratégias cotidianas para atingir homogeneamente a todos, além de estabelecer reforços disciplinares nos momentos escolares mais propícios à indisciplina e sobre as crianças consideradas mais problemáticas. Nessas condições, a significativa dimensão de eficiência no funcionamento dos livros de ocorrência se dá tanto na medida em que atinge a todos - e mesmo os que não estão nem estarão presentes nos livros, mas que se encontram sob a ameaça de estar -, quanto na medida em que atua especialmente sobre as crianças que experimentam de fato transgredir as normas e expectativas estabelecidas.

Ressalte-se que o processo cotidiano de efetivação desse ideal é intensamente ambíguo e conflitivo, sendo freqüentemente frustrado, ameaçado, afirmado e negado, tendo em vista, por exemplo, a visibilidade ou o "incômodo" provocado pelas crianças consideradas indisciplinadas. Por outro lado, a explicitação mesma do ideal da internalização a mais plena possível dos mecanismos de controle e de vigilância dentro de cada criança também é marcada por ambigüidades no cotidiano escolar contemporâneo, em meio, por exemplo, à afirmação recorrente de compromissos em torno da formação de cidadãos criativos, autônomos ou críticos, questão à qual voltarei neste texto.

\section{O IDEAL DO CONTROLE PLENO: FRUSTRAÇÃO, FRAGILIDADE E REFORÇO}

Não foi possível visualizar, nos livros de ocorrência, a especial incidência de determinadas séries, com os respectivos docentes responsáveis por elas, que pudesse indicar maior envolvimento com problemas disciplinares. No entanto, na entrevista ${ }^{6}$, a pedagoga avaliou que o professorado responsável pelas aulas "especiais" - Educação Física, Artes - e pela substituição das professoras regentes é o que mais apresenta dificuldade para assumir sua responsabilidade com as questões disciplinares, particularidade que também observei nos registros existentes nos livros de ocorrência. Conforme a pedagoga, a

6. Como fonte complementar de dados, realizei duas entrevistas com a pedagoga que permanecia na escola por mais tempo, a quem quero, mais uma vez, agradecer. 
Disciplina, vigilância e pedagogia

tendência desses docentes é a de encaminhar para as pedagogas ou para as professoras regentes as crianças que "tumultuam" as atividades.

Outro foco de maior incidência de problemas disciplinares refere-se aos momentos de "recreio", de troca de docentes ou de entrada e saída da escola, quando há necessidade de maior controle, uma vez que há um livro especialmente voltado para o disciplinamento nesses momentos, ao qual chamei livro de ocorrências "resumido". A pedagoga avaliou como particularmente positiva a época em que havia uma escala de docentes para ajudar as inspetoras a observar as crianças durante o horário do "recreio". Na entrevista, a pedagoga afirmou ainda que o "recreio" tem dois períodos de quinze minutos cada um: primeiro, saem as crianças menores; depois, as crianças de $3^{\mathrm{a}}$ e $4^{\mathrm{a}}$ séries, com cinco minutos de intervalo entre ambos, para que as turmas entrem e saiam. Eis algumas narrativas existentes no livro "resumido":

Ocorrência 2. A aluna Bianca série "x", Marcio série "x" na hora do recreio estavam brigando e jogando pedra um no outro e assim sendo os dois foram advertidos sendo que os mesmos pediram desculpas um para o outro. [Constam apenas as assinaturas dos dois alunos.]

Ocorrência 3. Os alunos Othon C. Furlan e Pablo B. Tosato foram indisciplinados em fila e desrespeitaram a professora (turma " $x$ "). [Constam as assinaturas dos dois alunos.]

Ocorrência 4. Os alunos da turma "x" sendo um deles Gastão F. Parize anda se comportando mal na hora do recreio passando a mão em outra aluna; se o mesmo tiver tal comportamento será suspenso. [Consta a assinatura do aluno especificamente citado.]

Ocorrência 5. O aluno Fulvio N. Benuzi estava brigando na hora da entrada com Fausto Percegona; se o mesmo continuar será suspenso. [Constam as assinaturas dos dois alunos.]

Ocorrência 6. Os alunos Gaspar X. Mastena, Raul B. Grando, Rodolfo M. Zacoti, estava pegando lanche em outras salas e não é a primeira vez. [Constam as assinaturas dos três alunos.]

Ocorrência 7. Os alunos Cláudio Bevilaqua e Altair B. C. dos Campos: brigaram na saída da escola às 17:00 horas se espancaram a socos e ponta pés. Tudo 
isso por causa de uma raia. $\bigcirc$ Claudio me parece ser o mais agressivo. [Constam as assinaturas de ambos, com as respectivas séries ao lado.]

Ocorrência 8. O aluno Francisco B. Saldanha da série "x", estava chutando os alunos na entrada da aula: esse menino só está dando muito trabalho a todos. [Consta a assinatura do aluno.]

Ocorrência 9. A aluna Isabel Mayer ameaçou de bater na aluna Marlene V. Larsen se o aluno Claudio [citado na ocorrência 7] da série " $x$ " não falasse mais com ela e se não namorasse mais com a Isabel. Após a ameaça a Isabel bateu no rosto da Marlene. [Constam as assinaturas das duas alunas e, surpreendentemente, também a do aluno mencionado.]

Ocorrência 10. O aluno Moysés Pombo da série "x" colou chiclete no cabelo do colega Lázaro. [Consta a assinatura de Moysés.]

Ocorrência II. O aluno Guilherme estava rindo das ordens que estavam sendo dadas pela direção. $\bigcirc$ mesmo foi tirado da sala de aula. [Consta a assinatura do aluno.]

Brigas e mau comportamento ocorridos no "recreio", nas filas, nos momentos de entrada e saída da escola. Tendo em vista que nesses momentos há necessidade de reforço da vigilância sobre as crianças - tanto que a escola destinava um livro de ocorrências especialmente voltado para eles -, cabe perguntar sobre que tipo de questões incide no fato de as crianças estarem mais propensas a apresentar problemas disciplinares nessas ocasiões. A questão pode ser abordada tendo em mente o que Foucault descreveu em termos das quatro funções exercidas pelo poder de tipo disciplinar no cotidiano das instituições: "a arte das distribuições", "o controle da atividade", "a organização das gêneses" e "a composição das forças" (Foucault, | 977, p. I30- I 52).

Deixando de lado esses complicados nomes e voltando à questão especificamente para o disciplinamento escolar, parece-me que o relevante é pensar na disciplina posta em funcionamento no contexto atual em termos das ações escolares que vinculam as crianças ao espaço, às atividades que desempenham, ao emprego do tempo ou à utilização de suas forças. Pode-se pensar que é exatamente quando há um afrouxamento da ação escolar na direção das funções apontadas por Foucault que a utilização dos livros de ocorrência se faz ainda mais necessária: quando os vínculos entre os corpos infantis e o espaço, no sentido 
Disciplina, vigilância e pedagogia

da fixação rigorosa dos lugares de cada um e da previsão das possíveis trocas e circulações, encontram-se relativamente suspensos; quando as codificações das formas de desenvolvimento das atividades, articulando estreitamente a criança ao tempo, aos atos, a seu corpo e aos objetos a serem manipulados, foram deixadas na sala de aula, assim como o cumprimento de objetivos, os pré-requisitos, as provas, os exercícios ou os encadeamentos curriculares meticulosamente definidos no sentido de encaminhar as aprendizagens.

Nesses momentos de reorganização e/ou de relaxamento relativo das obrigações ou dos ordenamentos escolares, as expressões corporais de parte das crianças se tornam particularmente problemáticas, como consta no bloco de exemplos antes apresentados: brigas, chutes, socos e pontapés, "guerra de pedras", furto de lanche, indisciplina na fila, namoros ou "passada de mão", chiclete no cabelo do colega, desrespeito à professora, risos das ordens dadas pela direção. Enfim, momentos especialmente evidentes de frustração e da fragilidade mesma do ideal de controle pleno sobre os corpos infantis, pois algumas crianças insistem em "tumultuar" as atividades escolares, "dando muito trabalho a todos", como constava de uma das ocorrências.

Isso não quer dizer que não haja ordenamentos nos "recreios" e demais momentos em que a incidência dos problemas disciplinares é maior. No entanto, nesses momentos, pode ser que parte das crianças ainda não esteja devidamente sintonizada com os enquadramentos escolares (entrada na escola), pode ser que esteja ansiosa ou apressada para livrar-se de tais enquadramentos (saída da escola), ou pode ser que se desvie dos comportamentos esperados, na medida em que experimenta alguns momentos de liberdade e maiores margens de movimentação ("recreio", Educação Física).

Assim é que há crianças que saem para o "recreio" feito "bombas atômicas prontas a explodir", metáfora que era muito utilizada no tempo em que eu dava aulas no ensino "primário". Outra situação emblemática era a do "recreio" em dias de chuva - dias sinistros, pois todos tendiam a se sentir angustiados: as professoras, porque não poderiam se distanciar por pouco que fosse das crianças e de seu papel controlador; e as crianças, porque não poderiam se distanciar das professoras e de seu papel submisso.

Ocorrência 12. Os alunos Napoleão e Orestes (série "x") no intervalo do recreio de chuva, abaixaram as calças da colega Malba. A mesma reagiu com chu- 
tes e pontapés. Foi alertado que na próxima ocorrência os pais tomarão ciência deste caso. [Constam a data abreviada e a assinatura da pedagoga.] A Profa Cloé veio avisar que dias atrás, os mesmos alunos abaixaram as calças do Reinaldo e Renê, colegas de sala, na saída para o recreio. Sugeri que seja trabalhado a questão de sexualidade c/ as crianças.

Ocorrência 13. O aluno Adroaldo Freitas Coutinho [outro aluno que está entre os "campeões de ocorrência"], na data de hoje, "x", desrespeitou a professora Raquel, da série " $x$ ", mandando-a "tomar no cu" e "se foder", quando a mesma comunicou a classe que o horário do recreio era o da chuva e que eles iriam permanecer na sala, saindo somente $\mathrm{p} / \mathrm{a}$ aula de Educação Física. [Constam a data abreviada, a rubrica da pedagoga e a assinatura do aluno.]

\section{A ESCOLA TAMBÉM PODE SER VIGIADA, CULPADA, PUNIDA?}

A vigilância sobre o corpo infantil, conforme o que aparece nas narrativas dos livros, pode ser analisada com base em dois grandes leques de necessidades: as relacionadas ao disciplinamento, em geral, e as especialmente relacionadas ao disciplinamento no que se refere às obrigações escolares de proteger a criança enquanto ela está sob sua responsabilidade. Quanto ao primeiro leque de necessidades, ao qual não me deterei aqui, o disciplinamento é feito, dentre outros aspectos, mediante a antiga tradição pedagógica de estruturar a aprendizagem a partir da extrema imobilidade do corpo infantil, pelas relações a serem estabelecidas entre o corpo da criança e o tempo, o espaço, as atividades a serem desenvolvidas etc.

Procuro deter-me agora no segundo leque de necessidades, ou seja, o que gira em torno da questão corporal com base nas pressões vividas pela escola visto que ela tem obrigações de zelar pela freqüência, guarda e proteção das crianças enquanto estas estão sob sua alçada. Muitas das narrativas que trazem problemas na Educação Física, problemas de falta, de fuga ou de brigas podem ser interpretadas particularmente nesse sentido. Aos "desavisados", certas narrativas sobre casos de fuga ou gazeteamento de aula, como as apresentadas a seguir, parecem se referir à fuga de presidiários, algo que, talvez ironicamente, atualize a provocação de Foucault de que as escolas apresentam desconcertantes semelhanças com as prisões. 
Disciplina, vigilância e pedagogia

Ocorrência 14. Os alunos Nivaldo C. Sprenger e Moysés Pombo [este último já citado na ocorrência 10] fugiram da escola no horário da aula de Educação Física com a professora Joyce. A Inspetora foi atrás e só conseguiu trazer de volta o Nivaldo. Por esse motivo os mesmos só poderão entrar na sala de aula acompanhados dos pais ou responsáveis. [Constam a data, a assinatura da pedagoga e a da mãe de Nivaldo.]

Ocorrência I5. O aluno Olívio, série “x”, estava gazeando a última aula (Ed. Física). Foi pego no flagrante. [Constam a data abreviada e a assinatura da pedagoga.]

No geral, as narrativas servem para proteger a escola de eventual culpabilização, funcionando como prova de que se tomou ciência e se encaminharam as devidas providências em relação a cada caso:

Ocorrência 16. Aos "x" dias do mês de "x" de "x" [ano], Dona Natália D. Fogiato, esteve na Escola, a pedido da orientadora educacional Letícia, para conversarmos sobre as faltas exageradas e várias gazetas de aula que o Olegário D. Fogiato vem cometendo. A orientadora por 6 vezes enviou bilhetes de alerta, solicitou inspetoras para ir a casa dos pais e não recebia retorno da família. Após ter ameaçado acionar o Conselho Tutelar, a mãe compareceu à Escola. Tivemos uma conversa franca sobre as atitudes indesejadas do menino e pedi mais apoio pois se o caso continuar, Olegário poderá reprovar por faltas e desinteresse aos estudos. A Escola não poderá assumir a responsabilidade sozinha, quando o menino gazear e the acontecer alguma coisa. Sem mais nada a declarar, firmo ser verdade. [Constam a data abreviada, as assinaturas da pedagoga e a da mãe.]

Ocorrência 17. $\bigcirc$ aluno Noel M. Vorobi, série " $x$ ", estava subindo na janela na hora do recreio no dia de hoje. (dia " $x$ "). [Consta apenas a assinatura do aluno.]

Ocorrência 18. No dia " $x$ " de "x" de " $x$ " [ano] esteve na minha sala a Sra. Erondina ao qual ficou ciente que seu filho Olavo Sampaio esteve em cima da laje ao qual foi pedido para descer e o mesmo não o fez. Pedimos ajuda da mãe para que não fique sendo só da responsabilidade da escola se algo mais sério acontecer, igual a quebra de um braço ou algo mais. A mãe acha correto a atitude tomada e se responsabiliza a tomar providências quanto ao caso. Esta ocorrência vai assinada por mim e a mãe em questão. [Constam as assinaturas da diretora e da mãe.] 
Ocorrência 19. Aos " $x$ " dias do mês de " $x$ " de hum mil novecentos e noventa e " $x$ ", a aluna Regina Maciel de Brito foi colocada na minha sala pela inspetora ao qual informou que a mesma sendo da série " $x$ " invadiu o recreio da primeira e da segunda série pulando o muro indo até a panificadora para comprar bolacha recheada tendo risco de vida e deixando todos apavorados pois a mesma poderia ter quebrado uma perna, pescoço ou braço e no caso a escola seria responsabilizada. Foi conversado com a mesma, esclarecido todos os fatos e conseqüências dos seus atos. A ocorrência vai assinada por mim e a aluna em questão. [Assinam a diretora e a aluna.]

Ocorrência 20. Os alunos Napoleão e Orestes [ambos citados na ocorrência 12] - série " $x$ " - aula de Ed. Física, brigaram e trocaram socos e pontapés. Saíram machucados e foram imediatamente atendidos. [Constam a data e a assinatura da pedagoga.]

Ocorrência 21. O aluno Caio Guerra Portela [outro que está entre os "campeões de ocorrência"], estava atirando pedra no horário do recreio e acabou atingindo a cabeça da aluna Nazaré, da série " $x$ ". O aluno foi advertido e só poderá entrar na escola se vier acompanhado dos pais ou responsáveis, pois a menina levou um corte na cabeça e foi levada ao posto de saúde. Caso ela precise de medicamentos, a família do Caio terá que arcar com as despesas. [Constam "Curitiba" e data por extenso, assinaturas da pedagoga e do pai do aluno; ao final, observação de que o aluno deu o nome do irmão, tentando enganar a supervisora.]

Esses são alguns dos exemplos dos quais emerge um dos elementos constitutivos da lógica que permeia o funcionamento dos livros: o receio de a escola ser acusada de negligência em suas funções de zelar pela guarda e proteção física das crianças. E mesmo com relação a ocorrências como a de número 17, na qual o motivo da repreensão não é explicitado, tendo em vista o conjunto das narrativas, é possível inferir tratar-se do mesmo tipo de motivação. Nessas condições, o tipo de questionamento que faço não vai na direção de pensar que a escola não tenha que se responsabilizar pelas crianças enquanto elas estão sob sua guarda; o problema gira em torno do tipo de lógica e implicações com que tal responsabilização funciona no cotidiano escolar. $\bigcirc$ que me parece problemático é que, se a escola precisa cercar-se de todo tipo de pre- 
cauções para que não venha a ser acusada de negligência - e muito do que anima os livros de ocorrência tem relação com isso -, é porque também se encontra em um conjunto de relações que a tornam constantemente vigiável, culpável e punível. Pois o pressuposto dos pais, do Estado, da imprensa e da sociedade em geral bem poderia ser o de acreditar que a escola de fato é responsável pelas crianças, geralmente dando mostras cotidianas de que faz tudo - que está a seu alcance para proteger-Ihes a integridade física e zelar por todas elas. Se o pressuposto fosse o da confiança, entender-se-ia que, apesar de todas as medidas preventivas de segurança tomadas pela escola, ainda assim os imprevistos são inevitáveis. No entanto, em direção semelhante à que foi apontada com relação às crianças (Ratto, 2002), o pressuposto parece ser, nesse caso, o de que a escola é culpada, até que prove o contrário.

Tais considerações levam novamente a Foucault, quando ele problematiza a emergência e o funcionamento de poderes de tipo disciplinar ao longo da história da Modernidade, em que os indivíduos passam a ser ordenados a partir da proliferação de saberes e técnicas normalizantes que atuam em perspectivas anatômicas, extensivas, "panópticas", intensamente produtivas, alastrando uma lógica criminosa, punitiva e vigilante para o conjunto das relações sociais.

Tendo em vista as especificidades do espaço da escola, Guimarães elabora duas importantes perguntas para nossos questionamentos sobre a disciplina escolar cotidiana: "A vigilância estaria integrada à relação pedagógica? Como ela se transforma no principal instrumento de controle dentro da escola?" (Guimarães, 2003, p.74). Eu tiraria da segunda pergunta o termo "principal", tendo em mente as articulações apontadas por Foucault quando analisa o conjunto das características das relações de poder de tipo disciplinar. No entanto, penso que tais perguntas não deixam de apresentar um produtivo desconcerto uma vez que atualizam a suspeita sobre uma finalidade da Pedagogia que pode ser considerada "pouco nobre", em meio a tantos discursos redentores e promissores no campo da educação. Não se trata de perseguir um caminho analítico de pura desqualificação ou negação da Pedagogia ou das ações escolares em si mesmas, mas de problematizar a funcionalidade ou os tipos de lógica que animam o que autores de diversas tendências teóricas apontam como sendo suas acentuadas tendências conservadoras e controladoras, traços fundamentais para os questionamentos em torno da disciplina escolar.

Nessa perspectiva, torna-se central pensar sobre a noção de ordem vigente nos discursos e práticas pedagógicas, tendo em vista que qualquer tipo 
de disciplina e de olhar sobre as crianças se refere aos ordenamentos escolares que estabelecem o conjunto dos comportamentos considerados, a princípio, necessários para que as aprendizagens possam se dar. Bauman é um autor que traz estimulantes considerações sobre a centralidade que uma determinada noção de ordem adquire nos rumos da Modernidade, com significativas implicações no campo pedagógico.

\section{ORDEM, MODERNIDADE E PEDAGOGIA}

Para Bauman, a ambivalência constitutiva da linguagem está presente também nas demais coisas do mundo, já que as nomeamos e definimos com a linguagem. E a nossa tendência "moderna" é a de experimentar a ambivalência como "desordem", como "falta de precisão", como "patologia da linguagem e do discurso", quando a desordem, a falta de precisão, a "falha da função segregadora (nomeadora)" fazem parte mesmo da prática lingüística, sendo seu "estado normal" (Bauman, 1999, p.9).

A linguagem, tendo em vista sua função nomeadora e classificatória, visa ordenar o mundo, buscando combater e, ao mesmo tempo, prevenir a ambivalência, a contingência, o acaso, a imprecisão. No entanto, na Modernidade, essa função de afirmar o que cada coisa do mundo é adquire contornos de obsessão, tendo em vista, por exemplo, o papel que o progresso, a cientificidade, o domínio sobre a natureza ou a racionalidade instrumental adquirem ao longo de sua constituição.

Os nomes são sempre expressões que, agrupando sob um único signo uma pluralidade quase infinita (ou talvez infinita mesmo) de coisas, tentam ir contra a diferença, enfeitiçando-nos com o sonho da possibilidade de domesticar a pluralidade sob o manto do signo. Uma conseqüência desse feitiço? A imagemfantasia de uma alcançável pureza da linguagem. [...] Uma outra conseqüência? Pensar que a impossibilidade da tradução completa/perfeita/biunívoca é um problema (da nossa incapacidade ou imperícia no manejo da linguagem), sem se dar conta de que o problema é, inversamente, pensar que é possível uma tradução total/verdadeira/completa. (Silveira, 2004, s.p)

Ainda de acordo com Bauman, resulta daí uma espécie de "cruzada" contra a ambivalência, uma luta que é "tanto autodestrutiva quanto autopropulsora" 
Disciplina, vigilância e pedagogia

(Bauman, 1999, p. 10). Quanto mais se age no sentido de definir, de classificar, de afirmar definitivamente "o que é cada coisa" (autopropulsão), mais se depara com ambivalências, com tudo "o que é", mas "não é só isso", também "pode ser outra coisa" (autodestrutividade), dada a questão de que, por exemplo, "ou a situação não pertence a qualquer das classes lingüisticamente discriminadas ou recai em várias classes ao mesmo tempo" (Bauman, 1999, p. 10).

E é interessante pensar na afirmação de Bauman de que a Modernidade inventou a ordem na medida em que esta se constituiu em problema, que passou a ser definida em conceito, em ação e em projeto, uma vez que no mundo anterior não se pensava "A" ordem, ao menos no sentido em que a Modernidade passou a pensá-la, ou seja, a partir de conotações apresentadas como as únicas possíveis. A natureza, pensada na forma do fluxo contínuo, da ausência de determinação ou de pré-ordenamentos, passa a ser vista como obstáculo ao progresso humano, devendo ser ordenada, contida, adaptada, dominada. "A ordem tornou-se uma questão de poder e o poder uma questão de vontade, força, cálculo" (Bauman, 1999, p. 13). A ordem tornou-se artificial, tornou-se fruto da intervenção humana, ainda que esta artificialidade inicial vá posteriormente buscar hegemonia em argumentos "naturalizantes". Dessa forma, a existência moderna desnaturalizou a ordem, passando a pensar e agir sobre o mundo colocando a intervenção humana onde antes se colocavam elementos transcendentais ou divinos.

E assim, a modo de obsessão, a Modernidade definiu o mundo em duas grandes "bifurcações": a ordem e o caos, na medida em que a desordem é construída como "pura negatividade", como aquilo sem o que não há sentido para a ordem, uma vez que toda sua positividade é afirmada por "pura oposição: "Sem a negatividade do caos, não há positividade da ordem; sem o caos, não há ordem" (Bauman, 1999, p. I 5). A existência moderna não pensa a ordem em meio a outras ordens possíveis. Aquilo que funciona como ordem, ao banir a ambigüidade de seu terreno, elimina também a possibilidade de algo ser também alguma outra coisa fora ou para além do que foi definido. Trata-se da

...luta da determinação contra a ambigüidade, da precisão semântica contra a ambivalência, da transparência contra a obscuridade, da clareza contra a confusão. [...] A ordem está continuamente engajada na guerra pela sobrevivência. $\bigcirc$ outro da ordem não é uma outra ordem: sua única alternativa é o caos. O outro 
da ordem é o miasma do indeterminado e do imprevisível. $\bigcirc$ outro é a incerteza, essa fonte e arquétipo de todo medo. Os tropos do "outro da ordem" são: a indefinibilidade, a incoerência, a incongruência, a incompatibilidade, a ilogicidade, a irracionalidade, a ambigüidade, a confusão, a incapacidade de decidir, a ambivalência. (Bauman, 1999, p. 14)

É bom frisar que não se trata da crítica a toda e qualquer noção de ordem, ou de pressupor que a busca pela ordem seja intrinsecamente desnecessária ou prejudicial. Bauman está criticando as especificidades por intermédio das quais uma certa noção de ordem foi instituída na Modernidade ocidental. Uma "vontade de ordem" que se impôs historicamente de modos totalitários, buscando combater toda ambigüidade possível. Tal obsessão pela ordem animou os projetos e as ações nos mais distintos campos da sociedade, algo que, portanto, pode ser identificado também no campo da constituição da Pedagogia e da escola moderna.

Antelo e Abramowski referem-se a esse tipo de tradição moderna na Pedagogia com o nome de Pedagogía pipona, que traduzi como "Pedagogia da completude" 7 , constantemente impulsionada pelos ideais de um ensino pleno, perfeito, harmonioso, negando fortemente tudo o que ameaça a realização plena de tais ideais: a ambigüidade, a contingência, os conflitos, a indeterminação. Uma tradição pedagógica, ainda hegemônica nos dias atuais, em que não há espaço para pensar e conviver com o que "diz não", já que o negativo, o conflito, a falta, aparece como aquilo que está, mas deveria não estar. Uma tradição pedagógica que pretende abolir - e promete como fazê-lo -, tudo "aquilo que

7. "Pipón/pipona" é uma gíria usada na Argentina, com dois significados básicos em português: pode significar o que está tranqüilo ou sossegado, ou o sujeito que está completo, "de barriga cheia", que está plena ou exageradamente satisfeito. É neste segundo sentido que a expressão Pedagogía pipona aparece na obra de Antelo e Abramowski: como aquela "satisfeita, [...] aquela que tem tudo, [uma] pedagogia plena e completa [...] para a qual nada lhe falta" (Antelo, 2000a, p.48, 51 ; minha tradução). Como não me pareceu bem traduzir Pedagogía pipona como "Pedagogia satisfeita ou plena" e aceitando as valiosas contribuições de Carlos Skliar como membro da banca examinadora de minha tese, preferi traduzi-la como "Pedagogia da completude". Conseqüentemente, quando os autores se referem ao que chamam de "Pedagogia do não-todo" para imaginar algo distinto, algo que aprenda a conviver com os conflitos, com o indeterminado, com o que falta, preferi a tradução "Pedagogia da incompletude". Para maiores esclarecimentos, ver Ratto (2004). Deixo aqui a sugestão de que se busque a leitura desse provocativo livro de Antelo e Abramowski (2000). 
Disciplina, vigilância e pedagogia

ameaça interromper o circuito normal das coisas [...], que vem a interromper certa ordem" (Antelo, Abramowski, 2000, p.80-8I, tradução minha).

Os autores referem-se a um "sonho totalitário" (Antelo, Abramowski, 2000, p.85, tradução minha ), a um "nirvana pedagógico" (Antelo, 2000, p.47, tradução minha ), a um "otimismo fundamentalista" (Antelo, Abramowski, 2000, p.8I, minha tradução), baseado no ideal - e, portanto, na meta - de que haja uma sociedade, um aluno, uma aprendizagem, sem conflitos, sem negatividades, sem faltas ou interrupções. Baseada nesses pressupostos - girando em torno de que a plenitude existe, sendo não apenas possível, como desejável -, essa tradição opera, mediante uma significativa vontade ordenadora, no campo do pensamento e da ação, produzindo e ao mesmo tempo buscando aniquilar tudo o que falta para que a educação possa realizar-se plenamente.

Nesse sentido, a Pedagogia e os sistemas escolares têm se constituído, ao longo das diversas tendências e embates de cada momento histórico, a partir de um profundo rechaço à indeterminação. Seus discursos hegemônicos apóiam-se em esquemas de causalidade linear, em redes causais de explicação baseadas no que aparece como as condições necessárias, inevitáveis ou determinantes para que a aprendizagem se realize plenamente.

Antelo faz um mapeamento interessante a respeito das definições que circulam sobre o necessário e o contingente.

Contingente: possibilidade de que algo aconteça. Fato que pode acontecer ou não acontecer. Coisa contingente. Eventual. Risco, perigo, evento. [...] Necessário: Determinado. Que se segue inevitavelmente a sua causa. Aquilo sem o qual (quer dizer a condição) não é possível viver. $\bigcirc$ que não é suscetível de ser de outra maneira de como é. (Antelo, 2000, p.|44-|45, tradução minha)

A tradição pedagógica é fortemente constituída pela busca dos a priori, dos elementos necessários que não podem faltar para o êxito educativo. Como afirma Antelo, "impossibilidade não é uma palavra agradável à tenacidade pedagógica metafísica. [...] É muito o que não pode ser de outra maneira de como é no campo da educação" (Antelo, 2000, p. I 50, tradução minha).

$\bigcirc$ autor problematiza em particular os postulados do que denomina "psicodidática", tendo em vista a hegemonia que um certo tipo de discurso alcançou nas definições da Pedagogia contemporânea. 
A psicodidática crê fervorosamente que aquele que aprende, aprende somente na medida em que leva a cabo, em que se cumpre, um processo psicodidático. Se uma criança não aprende é porque não se cumpre uma série de postulados psi que funcionam como condições necessárias para que algo da ordem da aprendizagem aconteça. (Antelo, 2000, p.139, tradução minha)

E o fracasso nessa cadeia causal costuma ser pensado como falta, das mais variadas ordens. Alguns desses postulados sobre os quais os autores se debruçam criticamente, são, por exemplo, os de que a aprendizagem - não qualquer uma, mas a efetiva aprendizagem - só se realiza quando há "interesse" e "motivação" das crianças, quando se parte de seus "saberes prévios" ou quando as aprendizagens se tornam "significativas", pois se articulam à realidade imediata das crianças. Conforme esse tipo de discurso, faltando tais condições, ocorrem os problemas de aprendizagem e, principalmente, para o que interessa especialmente aqui, ocorrem os problemas disciplinares.

No entanto, e apesar de tudo, constata-se que faltam aulas que funcionem plenamente, falta harmonia, entendimento, faltam aprendizagens significativas, falta disciplina.

Não há estratégia didática que permita livrar-nos dos "do fundo", dos que atentam contra o transcorrer da aula, interrompendo-a, dos desatentos, dos que resistem, dos sediciosos que se levantam e se sentam, dos ávidos da visita ao banheiro, dos que contaminam e parasitam (na) a classe, dos de sempre. (Antelo, Abramowski, 2000, p.79-80, tradução minha)

O combate à ambivalência, à contingência, ao indeterminado, ao que falta, também está presente na tradição pedagógica que define o que é ou deve ser a disciplina na escola. E, tendo em vista o que há de atual na questão lançada por Foucault de que as escolas apresentam (ainda) intrigantes semelhanças com as prisões ou os quartéis, não se trata da definição de uma disciplina, em meio a outras possíveis. Na mesma direção apontada por Bauman em termos da bifurcação entre ordem e desordem, a indisciplina, sendo a negação da disciplina, constitui-se "pura negatividade", funcionando apenas para afirmar e legitimar toda a "positividade" do que é estabelecido como disciplina. 
Disciplina, vigilância e pedagogia

A indisciplina costuma ser pensada como "aquilo que impede a disciplina de constituir-se como tal" (Antelo, 2000, p.65, tradução minha), não sendo apenas sua ausência, mas sua impossibilidade. E também se pode pensar que, no afã de combater tudo o que a nega, a vontade disciplinadora da escola seja tanto "autodestrutiva", quanto "autopropulsora", na direção do que antes foi citado no âmbito do pensamento de Bauman a respeito da noção hegemônica de ordem durante a Modernidade. Quanto mais se define, se esquadrinha, se busca produzir e controlar a criança disciplinada, mais se abre o campo de emergência para as crianças indisciplinadas, das que a qualquer momento podem não se enquadrar, não se adaptar, negar ou não corresponder aos padrões que estabelecem o que é a criança disciplinada. Sendo assim, a escola produz sua indisciplina diária.

Nesse sentido, é fundamental indagar "por que o combate ao que falta", "ao que diz não", "ao conflito"; é uma questão central na história da Pedagogia e dos sistemas escolares, pois esse é um dos pilares da definição das relações entre a disciplina e a indisciplina na escola. $O$ ideal parece ser o de que não haja crianças indisciplinadas na escola, que todas colaborem, entendam, aprendam, obedeçam, respeitem. Pensando que o conflito, a negação, a resistência são inerentes ao exercício do poder (cf., por exemplo, Foucault, 1982, 1999), e que não é possível, nem desejável, pensar uma relação da qual estejam banidos, trata-se de problematizar o que nos leva a agir em direção à anulação das diferenças, dos conflitos, daquilo que vemos como negatividades absolutas; trata-se de questionar que tipo de lógica, de Pedagogia, de cultura escolar, estabelece o que falta, baseada em quais pressupostos, apoiada em quais práticas, produzindo que sorte de efeitos.

Há uma forte tradição da "Pedagogia da completude", que se baseia na necessidade de vigilância constante, de controle rígido, extensivo ou pormenorizado do que acontece no cotidiano escolar, como, por exemplo, nas enraizadas homogeneizações de sentidos e usos do tempo ou do espaço escolar, no "engessamento" ao qual o corpo infantil é tradicionalmente submetido na escola, dentre outras características. Daí uma sobrecarga sobre seu papel disciplinador e, portanto, sobre o campo que define o que é a criança indisciplinada, pois são tantos os aspectos a serem controlados, homogeneizados, normalizados, que o campo da indisciplina não somente é produzido, quanto, em certo sentido, incentivado. Trata-se de problematizar a indisciplina em uma direção próxima da que Foucault (1999) pensou a sexualidade, ou seja, 
não tanto como o "inimigo", mas como o suporte para a multiplicação infinita das operações de disciplinamento.

Por exemplo, se a escola insiste em manter as crianças "parafusadas" nas carteiras, movimentando-se estritamente dentro dos rígidos padrões permitidos, ela induz a possibilidade de que muitas delas saiam como "bombas atômicas prontas a explodir" para o "recreio" ou de que apresentem problemas disciplinares nas aulas de Educação Física. Da mesma forma, só há problemas disciplinares durante as formações de filas porque a escola, nesse sentido, continua se parecendo com os quartéis, ou com as prisões, dado que, se não houvesse filas, não poderia haver indisciplina nas filas. E assim é que a indisciplina é produzida pela escola. Haveria, certamente, outros campos para a produção da indisciplina, mas não estes que há tanto tempo consomem as energias escolares. Quanto mais há o que vigiar, mais vigilância será necessária e mais se estenderá o campo para a transgressão, algo que coloca a engrenagem disciplinar sempre funcionando com certas margens de eficiência, mas também de significativa ineficiência.

É possível também se aproximar dessa lógica acentuadamente controladora pela pesquisa de Milstein e Mendes (1999). Eles fazem uma investigação de cunho etnográfico em escolas primárias argentinas, valendo-se de instrumentos como observações, entrevistas e realização de oficinas, com base em produções vinculadas ao que chamam de teoria social crítica, com referências a Marx, Foucault, Giddens, Larrosa e, especialmente, Bourdieu, apoiados

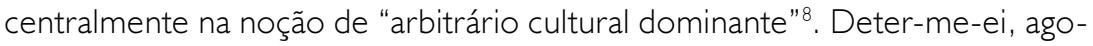
ra, em alguns dos elementos analíticos trazidos por Milstein e Mendes, pois me parecem ajudar tanto no sentido de esclarecer melhor o papel controlador desempenhado pela Pedagogia e pela escola na contemporaneidade, quanto

8. A partir da noção de "arbitrário cultural dominante", de Pierre Bourdieu, os autores tecem fecundas considerações a respeito de alguns dos principais significados e práticas atrelados à noção de ordem escolar, alguns construídos a partir das especificidades do trabalho na escola e outros circulantes na sociedade, em geral. O termo "dominante" é utilizado no sentido de "delimitar aqueles significados que predominam na cultura escolar e definem o sentido legítimo das práticas escolares, em relativa correspondência com os significados da estrutura social" (Milstein, Mendes, 1999, p.35, tradução minha), o que não significa desconsiderar que haja conflitos, disputas ou resistências com relação a esse predomínio de sentido. E o termo "arbitrário" aponta exatamente para o caráter não natural, nem inevitável, nem necessário desses significados e dessas práticas. 
Disciplina, vigilância e pedagogia

no de auxiliar possíveis articulações com uma certa tradição pedagógica e com a problemática da disciplina, como elemento ordenador do cotidiano escolar.

\section{PEDAGOGIA E CONTROLE: O EXEMPLO DOS JOGOS ESCOLARES}

Milstein e Mendes salientam a grande importância que as/os professoras/es presentes em sua pesquisa conferem às atividades que se apresentam na escola sob a forma de jogos, não perdendo de vista tratar-se do cotidiano das séries iniciais do ensino fundamental. Tais docentes assinalam as inúmeras vantagens pedagógicas que vêem na utilização dos jogos, no sentido da facilitação das aprendizagens de cunho intelectual, afetivo e moral, tendo por base uma proposta de ensino prazeroso, criativo, que motive os alunos e evite os problemas disciplinares.

A grande surpresa são as situações conflitivas, inesperadas e angustiantes por eles relatadas quando os jogos acontecem nas salas de aula: algumas crianças agitam-se muito, outras não querem participar, outras não entendem. "O resultado de muitos jogos que proponho é traumático tanto para mim quanto para as crianças, dado que produz nelas uma grande ansiedade e desordem e em mim um fracasso como coordenadora" (Milstein, Mendes, 1999, p.58, tradução minha) $)^{9}$. Conforme os autores, "o jogo que propunham não interessava às crianças, ou não as divertia, ou não se instalava na proposta com naturalidade, ou não o entendiam, ou faziam algo diferente do proposto, o que produzia, quase sempre, muita 'desordem'” (Milstein, Mendes, 1999, p.56, tradução minha).

As várias narrativas dos docentes apontam para uma tensão central, relacionada ao que esperam ou supõem que deve acontecer e o que na prática acontece quando as crianças jogam na escola. Os autores sistematizam dois tipos de interpretação para essa tensão baseados nos depoimentos dos docentes. Um deles remete à noção da falta, ou seja, a noção de que a aplicação do jogo resultou problemática porque faltou nos docentes ou nas crianças "alguma coisa": clareza nas explicações, adequação quanto ao momento de usá-lo, atenção ou interesse por parte das crianças etc. A outra remete às tensões apontadas pelos docentes em termos das contradições ou ambigüidades existentes entre respeitar os "interesses ou necessidades da criança" e ao mesmo

9. Tendo em vista a riqueza dos depoimentos colhidos dos docentes participantes da pesquisa de Milstein e Mendes, citarei partes de alguns deles. 
tempo a obrigação de corrigi-las, estabelecendo os hábitos valorizados pela escola (ordem/atenção/disciplina etc.).

Tudo isso remete os autores à identificação do que aparece como "arbitrário cultural escolar dominante" em termos dos sentidos predominantemente atribuídos ao jogo e à infância, algo que atua fortemente no cotidiano escolar, já que, nesse caso, os docentes continuam usando a estratégia dos jogos em sala, mesmo vivenciado recorrentes frustrações.

As análises feitas por Milstein e Mendes apontam para alguns pressupostos que articulam necessariamente infância e jogo, que funcionam como certezas inquestionáveis, "biologizadas" ou naturalizadas no senso comum pedagógico. Nas oficinas feitas com os docentes emergiram como parte do "arbitrário cultural dominante", termos definindo as crianças em certas ocasiões como

..."obedientes", "submissas", "caladinhas"; em outras ocasiões [as crianças são identificadas como] "desobedientes", "rebeldes", "contestadores". "Carinhosos", "mimosos", mas também "egoístas". "Espertos", "curiosos" e "inteligentes”, mas por momentos "estão na lua" e "se distraem facilmente". (Milstein, Mendes, 1999, p.62, tradução minha)

Milstein e Mendes destacam aí duas características. Uma aponta para o acento dado pelos docentes ao que faltaria na criança, suas "carências" ou "defeitos", uma vez que a ênfase das colocações recaía sempre naquilo que incomodava mais, ou seja, na mobilidade, agitação, contestação ou na desobediência das crianças. A outra aponta para o permanente duplo sentido das críticas feitas pelos docentes, marcadas por "uma insuperável ambivalência ou ambigüidade: de um lado..., mas por outro lado..." (Milstein, Mendes, 1999, p.63, tradução minha) $)^{10}$.

Tais características remetem ao processo histórico tanto de "pedagogização" ou de "infantilização do jogo", conforme os autores, quanto de "infantilização da criança", este último termo acrescentado por mim. A "infantilização da criança" associa-se ao que é discutido por vários autores e autoras (cf., por exem-

10. Situar ambigüidades ou contradições é parte recorrente da argumentação desses autores. No que se refere às minhas intenções, passarei a citá-las não no sentido de aludir a uma suposta ou necessária superação, mas na direção de detalhar os conteúdos presentes nos discursos e nas práticas pedagógicas da atualidade. 
Disciplina, vigilância e pedagogia

plo, Bujes, 2002, Corazza, 2002, Narodowski, 1994), quando, por exemplo, estudam a própria invenção da infância, na passagem entre a Idade Média e a Idade Moderna. Na idade média as crianças não contavam com espaços, instituições ou saberes especificamente voltados para elas, crescendo em meio às práticas sociais dos adultos, enquanto na Idade Moderna se desenvolvem saberes e técnicas que vão construindo a infância a partir de características específicas necessárias, universais, naturais ou biológicas, com ênfase nos traços de dependência, imaturidade e desprestígio, na medida em que são tomados como padrão ideal os significados construídos em termos do mundo adulto.

A ambigüidade nos comportamentos das crianças quando jogam responde à construção de um sujeito desvalorizado, ou valorizado por traços de pouco prestígio (sensibilidade, fragilidade, afetividade, emotividade), que, tanto pelo que tem, como pelo que não tem, pelo que é, como pelo que não é, resulta puerilizado. [...] $\bigcirc$ jogo - essa atividade "natural" das crianças - é interpretado como pouco sério, relevante ou significativo por contraposição às práticas sociais da vida adulta. Assim, vem-se produzindo o processo de infantilização do jogo, quer dizer, sua desvalorização como não prática dos adultos e sua desvinculação da vida cultural, ao transformá-lo em uma sorte de atividade transitória, ainda que necessária, em certa etapa do desenvolvimento evolutivo dos indivíduos. (Milstein, Mendes, 1999, p.64-65, tradução minha)

Vinculado a tais noções, o jogo é infantilizado, aparecendo como algo necessário para o "bom" desenvolvimento infantil, ainda que também sujeito a desqualificações, porque os discursos pedagógicos supõem que deva ser progressivamente abandonado pela escola, na medida em que se aparta da seriedade do mundo adulto, mundo para o qual as crianças estão sendo preparadas para viver". Os autores assinalam que a atividade de jogar, entendida como algo típico da criança, é historicamente transposta para o universo escolar, tendo

1।. Vale notar que, se de um lado as práticas de jogos na sala de aula tendem a decrescer, na medida em que a escolarização avança - ou em que as crianças vão se tornando adultas -, por outro lado cada vez mais os jogos aparecem como estratégias relevantes na educação e em programas de treinamento de adultos, como, por exemplo, nos utilizados no campo empresarial (programas de qualidade total etc.). Se isso faz sentido, que tipo de lógica pode estar movendo essa dinâmica? 
em vista três exigências básicas. A exigência de que o jogo colabore ou instrumente as aprendizagens consideradas fundamentais para as crianças, no campo da matemática, língua etc.; a de que seja considerado como prática que pode revelar possíveis "distúrbios" em seu desenvolvimento; e a de que seja tomado como uma das formas importantes de corrigir hábitos vistos como inadequados, que "prazerosamente" podem converter-se em adequados, levando em conta a predisposição "natural" da criança para o jogo.

Como apontam Milstein e Mendes, os usos escolares do jogo são, assim, especialmente vinculados aos significados que estabelecem o que é a ordem no cotidiano escolar - ordenamento do tempo, do espaço, ordem curricular, moral etc. -, sendo direcionados no sentido de ensiná-la, reforçá-la, internalizá-la. A "pedagogização do jogo" é ainda explicada pelos autores, na medida em que o jogo, tal como costuma ser jogado fora da escola, é transposto para a lógica escolar.

Os jogos escolares da sala têm objetivos que os orientam, relativamente alheios ao jogo em si mesmo, claros e certeiros, relacionados com o ensino e a aprendizagem e, portanto, vinculados a necessidades individuais de rendimentos e comportamentos; a ordem está predeterminada com independência da atividade e se desenvolve dentro dos limites espaço-temporais simbólicos próprios da ordem escolar; sempre implicam a intenção de se conectar com o sentido de realidade precisamente porque supõem e a apreensão de algum aspecto do real. (Milstein, Mendes, 1999, p.69, tradução minha)

Já os jogos como práticas sociais caracterizam-se por apresentar uma ordem com certas margens de flexibilidade, expressando objetivos relativamente incertos, pois remetem ao universo do jogo em si mesmo, que se verifica mediante a invenção de tempos e espaços simbólicos que reordenam a realidade, "ficcionalizando-a" de modo relativamente independente da ordem moral. Tais jogos tendem a se dar a partir das tradições que lhes são próprias, sendo que as brigas ou os conflitos não os interrompem necessariamente: basta haver a disposição para continuar jogando.

Os que participam dos jogos escolares na sala de aula necessitam fazê-lo dentro do enquadramento "isto é a escola". Daí que os conflitos e brigas entendam-se como 
Disciplina, vigilância e pedagogia

perturbações e costumem ocasionar a interrupção da atividade. Este "jogo" está previamente "armado" pelo professor, que muito ocasionalmente joga, mas sempre coordena, dirige, avalia. Vive-se como um problema o fato de que alguém prefira não participar, e isso em geral tem mais relação com uma "tradição" didática que com uma tradição de jogo. (Milstein, Mendes, 1999, p.70, tradução minha)

E essa tradição didático-pedagógica remete à pretensão totalizante de controlar o mais possível tudo o que acontece no processo educativo das crianças, sob a minuciosa regulação que a lógica escolar busca efetuar. No caso da utilização do jogo na escola, dizem os autores, suas implicações finais remetem "à produção da subjetividade do sujeito adaptado e 'normal', ao controle do imaginário das crianças como um dos aspectos-chave de sua socialização" (Milstein, Mendes, 1999, p.55, tradução minha). Busca-se cooptar sua dinâmica própria, deslocando-a para a lógica escolar, na qual o jogo é convertido em instrumento para atingir especialmente o que se consideram os verdadeiros fins educacionais, ou seja, aqueles relacionados às aprendizagens cognitivas ou morais, seja no sentido de facilitá-las, seja de fixá-las ou corrigi-las. É por isso que freqüentemente tais manobras ocasionam conflitos, angústias e frustrações. A escola trata da "constante necessidade de canalizar, adaptar, corrigir o jogo das crianças para tornar suas ações compatíveis com os mandatos da socialização normativa, disciplinadora e homogeneizadora" (Milstein, Mendes, 1999, p.72, tradução minha).

Penso que esse tipo de características pode ser aproveitado para ilustrar a lógica geral presente quando se afirma que algo foi "pedagogizado", tendo em vista as tradições da Pedagogia moderna. Assim, a "pedagogização do jogo" (e de tudo o mais que é usado na lógica escolar) refere-se a esses tipos de dinâmicas necessariamente instrumentais - justificadas a partir de necessidades e fins superiores -, vinculadas à exigência da constante intervenção do professor em sentidos controladores e às várias pretensões totalizantes no direcionamento dos comportamentos infantis. Tal "pedagogização" é indissociável do que se entende por infância, o que remete aos processos de "infantilização das crianças", ou seja, aos discursos e práticas pedagógicas que constituem a infância com base no que definem como suas características universais e necessárias, acentuando traços de dependência, imaturidade e desprestígio.

Em direções similares, esses autores abordam o que chamam de estética no cotidiano escolar, entendida para além do que acontece estritamente nas 
aulas de Educação Artística e tendo em mente como o bonito/belo e o feio são ensinados na escola. Não me deterei nesses aspectos, mas deixo aqui a sugestão de que se busque a leitura desse precioso livro.

\section{A VIGILÂNCIA ESTARIA INTEGRADA À RELAÇÃO PEDAGÓGICA?}

Assim, a necessidade de constante vigilância remete a esse tipo de tradição pedagógica que, apesar de pressupor "positividades" na condição infantil - seu caráter "criativo", "espontâneo", "original", "disponível" -, tende a enfatizar os traços que demandam intervenções instrumentais, corretivas e controladoras. A imperiosidade dessa forma de observação, voltada para a vigilância, pode ser especialmente notada em narrativas do seguinte tipo:

Ocorrência 22. $\bigcirc$ aluno Clodoaldo Silva Sampaio, na data de hoje, [data] " $x$ ", desde a hora da entrada está infringindo as normas da escola. Primeiramente, a professora Rejane trouxe-o para a Coordenação pois o mesmo disse que sua mãe viria buscá-lo. Após confirmar com as Pedagogas que isso não era verdade, aluno e professora voltaram para sala. Pouco tempo depois, Clodoaldo estava novamente na sala da Coordenação sem a autorização da professora, que teve que sair da sala, deixando os outros alunos, para vir atrás do Clodoaldo. [...]

Ocorrência 23. Aos " $x$ " dias de "x" [mês] de " $x$ " [ano], foi convocado entrevista com a professora Amanda para que ela pudesse explicar o fato ocorrido ontem (dia " $x "$ ") com a turma "x", a qual a professora assumia. A Amanda soltou a turma 10 minutos antes para brincar livremente e acabou sumindo todo o material da aluna Jussara. A pedagoga colocou a necessidade de se fazer uma atividade dirigida mesmo que seja uma brincadeira fora de sala e que as malas fiquem na sala com a porta trancada. [Constam a data abreviada e a assinatura da pedagoga.]

Ocorrência 24. Aos " $x$ " dias do mês de " $x$ " de hum mil novecentos e noventa e " $x$ ", foram trazidos a sala da Coordenação os alunos: Elbio B. Lisboa, Heitor M. Severo, Gaudino O. Dressler e Beatriz V. Porto da série "x", para resolver um problema de briga entre os mesmos. Segundo os alunos a briga teve início no momento em que a professora Lavínia [nome da disciplina] se ausentou da sala para buscar um xerox, na sala ao lado. O Elbio bateu na Beatriz com uma corrente de clips, porque ela estava apagando o quadro. Os alunos se desculparam 
Disciplina, vigilância e pedagogia

entre si na presença da professora e das pedagogas. [Constam "Curitiba", data por extenso, as assinaturas de duas pedagogas e outra, irreconhecível.]

Na primeira ocorrência, menciona-se o inconveniente de a professora ter "que sair da sala, deixando os outros alunos [sozinhos] para vir atrás do Clodoaldo". Na segunda, o problema acontece porque a vigilância não foi devidamente operacionalizada. E é interessante notar que um dos encaminhamentos apresentados para evitar novos problemas semelhantes é o de buscar assegurar o controle e a vigilância, mesmo quando as crianças brincam livremente, através da sugestão "de se fazer uma atividade dirigida". E no terceiro exemplo, há a narrativa sobre uma briga ocorrida justamente quando a professora "se ausentou da sala para buscar um xerox".

Assim, a dimensão vigilante aqui problematizada, ou o que há de criminoso e de pecaminoso na lógica disciplinar que impulsiona os livros de ocorrência, não está associada a toda e qualquer Pedagogia, mas a um tipo específico de tradição pedagógica, ainda fortemente localizável no cotidiano escolar atual, na qual a constante necessidade de vigilância se faz imprescindível. Não se trata de pressupor que tudo o que acontece diariamente na escola vincula-se ao tipo de tradição pedagógica delineada anteriormente. No entanto, quando se trata das especificidades apontadas no funcionamento dos livros de ocorrência que pesquisei, as vinculações com tal tradição são vistas aqui como fundamentais.

Mais uma vez, recordo minhas experiências como professora "primária". Corriam-se muitos riscos ao deixar as crianças "abandonadas à sua própria sorte". Duas das principais "receitas" para evitar problemas e confusões eram manter as crianças sempre trabalhando e evitar deixá-las sozinhas. Assim, um dos grandes "fantasmas" da indisciplina - a ausência do olhar vigilante da/o docente e das demais autoridades escolares -, ainda parece estar bem vivo no cotidiano escolar.

\section{REFERÊNCIAS BIBLIOGRÁFICAS}

ANTELO, E. De los procesos pedagógicos: la retracción de lo necesario en educación. In: ANTELO, E.; ABRAMOWSKI, A. L. El Renegar de la escuela: desinterés, apatía, aburrimiento, violencia y indisciplina. Rosario: Homo Sapiens, 2000. p. I35-171. 
. La Educación que hace falta: in-disciplina y violencia escolar. In: ANTELO, E.; ABRAMOWSKI, A. L. El Renegar de la escuela: desinterés, apatía, aburrimiento, violencia y indisciplina. Rosario: Homo Sapiens, 2000. p.47-77.

ANTELO, E.; ABRAMOWSKI, A. L. Clases perfectas, chicos conocidos y relaciones peligrosas: ¿Como abandonar la pedagogía "Ingalls"?, o El chirriar de los poli-modales. In: . El Renegar de la escuela: desinterés, apatía, aburrimiento, violencia y indisciplina. Rosario: Homo Sapiens, 2000. p.79-93.

BAUMAN, Z. Modernidade e ambivalência. Rio de Janeiro: Jorge Zahar, 1999.

BUJES, M. I. E. Infância e maquinarias. Rio de Janeiro: DP\&A, 2002.

CORAZZA, S. M. Infância e educação: era uma vez... Quer que conte outra vez? Petrópolis: Vozes, 2002.

FOUCAULT, M. História da sexualidade /: a vontade de saber. Rio de Janeiro: Graal, 1999. Microfísica do poder. 3. ed. Rio de Janeiro: Graal, 1982.

Vigiar e punir. Petrópolis: Vozes, 1977.

FURLÁN, A. La Cuestión de la disciplina: los recovecos de la experiencia escolar. In: GVIRTZ, S. (comp.). Textos para repensar el día a día escolar. sobre cuerpos, vestuarios, espacios, lenguajes, ritos y modos de convivencia en nuestra escuela. Buenos Aires: Santillana, 2000. p. 17-58.

GUIMARÃES, A. M. Vigilância, punição e depredação escolar. Campinas: Papirus, 2003.

MILSTEIN, D.; MENDES, H. La Escuela en el cuerpo: estudios sobre el orden escolar y la construcción social de los alumnos en escuelas primarias. Madrid, Buenos Aires: Miño y Dávila, 1999.

NARODOWSKI, M. Infancia y poder. la conformación de la pedagogía moderna. Buenos Aires: Aique, 1994.

RATTO, A. L. S. Cenários criminosos e pecaminosos nos livros de ocorrência de uma escola pública. Revista Brasileira de Educação, São Paulo, n.20, p.95-106, 2002.

. Livros de ocorrência: disciplina, normalização e subjetivação. Porto Alegre, 2004. Tese (dout.) Programa de Pós-Graduação em Educação, Faculdade de Educação, Universidade Federal do Rio Grande do Sul.

SILVEIRA, R. M. H. Correspondência com Alfredo Veiga-Neto, jul. 2004.

Recebido em: agosto 2005

Aprovado para publicação em: novembro 2005 